\title{
Cognitive Development
}

National Cancer Institute

\section{Source}

National Cancer Institute. Cognitive Development. NCI Thesaurus. Code C81241.

The evolution of an individual's problem solving skills, memory, language development, and ability to process information about their environment. 